\title{
Statistical Analyses of Optimum Partial Replacement of Cement by Fly Ash Based on Complete Consumption of Calcium Hydroxide
}

\author{
Winai Ouypornprasert ${ }^{1, a}$, Narong Traitruengtatsana ${ }^{2}$ and Kong Kamollertvara ${ }^{2}$ \\ ${ }^{1}$ Department of Civil Engineering, College of Engineering, Rangsit University 12000 Pathumthani, Thailand \\ ${ }^{2}$ Asia Group (1999) Co., Ltd., King Rama II Rd., Bangmod, 10150 Bangkok, Thailand
}

\begin{abstract}
The objectives of this technical paper were to propose the optimum partial replacement of cement by fly ash based on the complete consumption of calcium hydroxide from hydration reactions of cement and the long-term strength activity index based on equivalent calcium silicate hydrate as well as the propagation of uncertainty due to randomness inherent in main chemical compositions in cement and fly ash. Firstly the hydration- and pozzolanic reactions as well as stoichiometry were reviewed. Then the optimum partial replacement of cement by fly ash was formulated. After that the propagation of uncertainty due to main chemical compositions in cement and fly ash was discussed and the reliability analyses for applying the suitable replacement were reviewed. Finally an applicability of the concepts mentioned above based on statistical data of materials available was demonstrated. The results from analyses were consistent with the testing results by other researchers. The results of this study provided guidelines of suitable utilization of fly ash for partial replacement of cement. It was interesting to note that these concepts could be extended to optimize partial replacement of cement by other types of pozzolan which were described in the other papers of the authors.
\end{abstract}

\section{Introduction}

Cement contents in concrete is the main cost for the concrete production. The reduction of cement content in concrete mix proportion would lower the cost of concrete and would increase the competitiveness in marketing. Therefore the probabilistic concrete mix design for mass production of concrete has been commercially applied [1]. Dumrongsil, Chatveera and Ouypornprasert [2] studied the suitable partial replacement of cement by rice husk ash (RHA). In this study the optimum replacement of cement by RHA was derived by the concept of calcium oxide equivalent. Results showed that the values of compressive strength of concrete mixed with RHA of the age less than 28 days tend to be lower than those of concrete mixed with Ordinary Portland Cement (OPC). However with suitable replacements of cement by RHA the values of compressive strength of concrete can be higher than those of ordinary concrete even at the early age [3]. The major reason might be the heat of hydration of cement mixed with pozzolan could surpass that of OPC [4]. Furthermore the optimum partial replacement of cement by RHA could be predicted accurately based on the concept of complete consumption of calcium hydroxide [5].

In this technical paper the optimum replacement of cement by fly ash (FA) based on stoichiometry of complete consumption of calcium hydroxide from hydration of cement and pozzolanic reactions of pozzolan substances as well as the long-term strength Activity index based on Equivalent Strength of Calcium Silicate Hydrates (C-S-H) is proposed. Since the chemical compositions of cement and FA are varied in the production process, propagation of uncertainty with respect to main chemical compositions will also be discussed. To assure the quality of concrete mixed with FA the suitable replacement of cement by FA should be determined with the target confidence interval. Once the particular replacement is selected the distribution of the long-term strength Activity index could be obtained. Then reliability of the selected replacement could be determined accurately by Monte-Carlo simulations or approximately by the advanced First-Order SecondMoment (FOSM) method. The applicability of the proposed formulations could be demonstrated by a set of data available in hand.

\section{Objectives}

The objectives of this study were to

1) formulate the optimum replacement of cement by fly ash based on the complete consumption of calcium hydroxide from hydration reactions of cement,

2) propose the long-term strength Activity index based on equivalent calcium silicate hydrate,

3) analyze the propagation of uncertainty of the optimum replacement of cement by fly ash in terms

\footnotetext{
${ }^{\mathrm{a}}$ Winai Ouypornprasert: owinai@yahoo.com
} 
of variation of main chemical compositions in cement and fly ash,

4) review the reliability analyses for utilizing the optimum replacement of cement by fly ash,

5) demonstrate the applicability of the proposed concepts.

\section{Materials and methods}

\subsection{General remarks}

It is usual for the cement chemist to use the following abbreviations for discussions about hydration reactions of cement and pozzolanic reactions [6]: $C$ for calcium oxide $(\mathrm{CaO}), \mathrm{S}$ for silicon dioxide $\left(\mathrm{SiO}_{2}\right)$, $\mathrm{H}$ for water $\left(\mathrm{H}_{2} \mathrm{O}\right), \mathrm{A}$ for aluminum oxide $\left(\mathrm{Al}_{2} \mathrm{O}_{3}\right)$, $\mathrm{F}$ for ferric oxide $\left(\mathrm{Fe}_{2} \mathrm{O}_{3}\right), \quad \mathrm{CH}$ for calcium hydroxide $\left(\mathrm{Ca}(\mathrm{OH})_{2}\right), \quad \mathrm{C}_{3} \mathrm{~S}$ for tricalcium silicate (3 $\left.\mathrm{CaO} \cdot \mathrm{SiO}_{2}\right), \quad \mathrm{C}_{2} \mathrm{~S}$ for dicalcium silicate ( $2 \mathrm{CaO} \cdot \mathrm{SiO}_{2}$ ), $\quad \mathrm{C}_{3} \mathrm{~A}$ for tricalcium aluminate (3 $\left.\mathrm{CaO} \cdot \mathrm{Al}_{2} \mathrm{O}_{3}\right), \quad \mathrm{C}_{4} \mathrm{AF}$ for tetracalcium alumino ferrite $\quad\left(4 \mathrm{CaO} \cdot \mathrm{Al}_{2} \mathrm{O}_{3} \cdot \mathrm{Fe}_{2} \mathrm{O}_{3}\right), \quad \mathrm{C}_{3} \mathrm{~S}_{2} \mathrm{H}_{3}$ or $\mathrm{C}-\mathrm{S}-\mathrm{H}$ for calcium silicate hydrate ( $\left.3 \mathrm{CaO} \cdot 2 \mathrm{SiO}_{2} \cdot 3 \mathrm{H}_{2} \mathrm{O}\right), \quad \mathrm{C}_{3} \mathrm{AH}_{6}$ for calcium aluminate hydrate $\left(3 \mathrm{CaO} \cdot \mathrm{Al}_{2} \mathrm{O}_{3} \cdot 6 \mathrm{H}_{2} \mathrm{O}\right)$ and $\mathrm{C}_{3} \mathrm{FH}_{6}$ for calcium ferrite hydrate ( $3 \mathrm{CaO} \cdot \mathrm{Al}_{2} \mathrm{O}_{3} \cdot 6 \mathrm{H}_{2} \mathrm{O}$ ).

\subsection{Hydration reactions, pozzolanic Reactions and stoichiometry}

\subsubsection{Hydration reactions}

3.2.1.1 Hydration reaction of tricalcium silicate $\left(C_{3} S\right)$

$$
\begin{aligned}
& 2\left(3 \mathrm{CaO} \cdot \mathrm{SiO}_{2}\right)+6 \mathrm{H}_{2} \mathrm{O} \rightarrow \\
& 3 \mathrm{CaO} \cdot 2 \mathrm{SiO}_{2} \cdot 3 \mathrm{H}_{2} \mathrm{O}+3 \mathrm{Ca}(\mathrm{OH})_{2} \\
& 2 \mathrm{C}_{3} \mathrm{~S}+6 \mathrm{H} \rightarrow \mathrm{C}_{3} \mathrm{~S}_{2} \mathrm{H}_{3}+3 \mathrm{CH}
\end{aligned}
$$

3.2.1.2 Hydration reaction of dicalcium silicate $\left(C_{2} S\right)$

$$
\begin{aligned}
& 2\left(2 \mathrm{CaO} \cdot \mathrm{SiO}_{2}\right)+4 \mathrm{H}_{2} \mathrm{O} \rightarrow \\
& 3 \mathrm{CaO} \cdot 2 \mathrm{SiO}_{2} \cdot 3 \mathrm{H}_{2} \mathrm{O}+\mathrm{Ca}(\mathrm{OH})_{2}
\end{aligned}
$$

$$
2 \mathrm{C}_{2} \mathrm{~S}+4 \mathrm{H} \rightarrow \mathrm{C}_{3} \mathrm{~S}_{2} \mathrm{H}_{3}+\mathrm{CH}
$$

3.2.1.3 Hydration reaction of tricalcium aluminate ( $\left.C_{3} A\right)$

$$
\begin{gathered}
3 \mathrm{CaO} \cdot \mathrm{AlO}_{3}+6 \mathrm{H}_{2} \mathrm{O} \rightarrow \\
3 \mathrm{CaO} \cdot \mathrm{Al}_{2} \mathrm{O}_{3} \cdot 6 \mathrm{H}_{2} \mathrm{O} \\
\mathrm{C}_{3} \mathrm{~A}+6 \mathrm{H} \rightarrow \mathrm{C}_{3} \mathrm{AH}_{6}
\end{gathered}
$$

3.2.1.4 Hydration reaction of tetracalcium alumino ferrite $\left(C_{4} A F\right)$

$$
\begin{gathered}
4 \mathrm{CaO} \cdot \mathrm{Al}_{2} \mathrm{O}_{3} \cdot \mathrm{Fe}_{2} \mathrm{O}_{3}+2\left(\mathrm{Ca}(\mathrm{OH})_{2}\right)+10 \mathrm{H}_{2} \mathrm{O} \rightarrow \\
3 \mathrm{CaO} \cdot \mathrm{Al}_{2} \mathrm{O}_{3} \cdot 6 \mathrm{H}_{2} \mathrm{O}+3 \mathrm{CaO} \cdot \mathrm{Fe}_{2} \mathrm{O}_{3} \cdot 6 \mathrm{H}_{2} \mathrm{O} \\
\mathrm{C}_{4} \mathrm{AF}+2 \mathrm{CH}+10 \mathrm{H} \rightarrow \mathrm{C}_{3} \mathrm{AH}_{6}+\mathrm{C}_{3} \mathrm{FH}_{6}
\end{gathered}
$$

\subsubsection{Pozzolanic reactions}

3.2.2.1 Additional calcium hydroxide from calcium oxide $(\mathrm{CaO})$ in pozzolan

$$
\begin{aligned}
\mathrm{CaO}+\mathrm{H}_{2} \mathrm{O} & \rightarrow \mathrm{Ca}(\mathrm{OH})_{2} \\
\mathrm{C}+\mathrm{H} & \rightarrow \mathrm{CH}
\end{aligned}
$$

3.2.2.2 Pozzolanic reaction of silicon dioxide $\left(\mathrm{SiO}_{2}\right)$

$$
\begin{aligned}
& 3 \mathrm{Ca}(\mathrm{OH})_{2}+2 \mathrm{SiO}_{2} \rightarrow \\
& 3 \mathrm{CaO} \cdot 2 \mathrm{SiO}_{2} \cdot 3 \mathrm{H}_{2} \mathrm{O} \\
& 3 \mathrm{CH}+2 \mathrm{~S} \rightarrow \mathrm{C}_{3} \mathrm{~S}_{2} \mathrm{H}_{3}
\end{aligned}
$$

3.2.2.3 Pozzolanic reaction of aluminium oxide $\left(\mathrm{Al}_{2} \mathrm{O}_{3}\right)$

$$
\begin{gathered}
3 \mathrm{Ca}(\mathrm{OH})_{2}+2 \mathrm{Al}_{2} \mathrm{O}_{3} \rightarrow \\
3 \mathrm{CaO} \cdot 2 \mathrm{Al}_{2} \mathrm{O}_{3} \cdot 3 \mathrm{H}_{2} \mathrm{O} \\
3 \mathrm{CH}+2 \mathrm{~A} \rightarrow \mathrm{C}_{3} \mathrm{~A}_{2} \mathrm{H}_{3}
\end{gathered}
$$

\subsection{Stoichiometry}

Atomic and molecular weights of all substances related in stoichiometry of hydration and pozzolanic reactions are summarized in Table $1-4$.

Table 1. Atomic weight of elements related in hydration- and pozzolanic reactions.

\begin{tabular}{|l|l|l|l|l|l|l|}
\hline Element & $\mathrm{H}$ & $\mathrm{O}$ & $\mathrm{Al}$ & $\mathrm{Si}$ & $\mathrm{Ca}$ & $\mathrm{Fe}$ \\
\hline
\end{tabular}




\begin{tabular}{|l|l|l|l|l|l|l|}
\hline $\begin{array}{c}\text { Atomic } \\
\text { Weight }\end{array}$ & 1 & 16.00 & 26.98 & 28.09 & 40.08 & 55.85 \\
\hline
\end{tabular}

Table 2. Molecular weight of main chemical components in cement.

\begin{tabular}{|c|c|c|c|c|}
\hline Compound & $\boldsymbol{C}_{3} \boldsymbol{S}$ & $\boldsymbol{C}_{2} \boldsymbol{S}$ & $\boldsymbol{C}_{3} \boldsymbol{A}$ & $\boldsymbol{C}_{4} \boldsymbol{A F}$ \\
\hline Molecular Weight $(\mathrm{g} / \mathrm{mol})$ & 228.2 & 172.2 & 270.0 & 483.1 \\
\hline
\end{tabular}

Table 3. Molecular weight of main chemical components in cement, and fly ash.

\begin{tabular}{|c|c|c|c|c|}
\hline Compound & $\mathrm{CaO}$ & $\mathrm{SiO}_{2}$ & $\mathrm{Al}_{2} \boldsymbol{O}_{3}$ & $\mathrm{Fe}_{2} \boldsymbol{O}_{3}$ \\
\hline Molecular Weight (g/mol) & 56.1 & 60.1 & 102.0 & 156.7 \\
\hline
\end{tabular}

Table 4. Molecular weight of chemical components related in hydration- and pozzolanic reactions.

\begin{tabular}{|c|c|c|c|c|c|}
\hline $\begin{array}{c}\text { Chemical } \\
\text { Components }\end{array}$ & $\mathrm{H}_{2} \boldsymbol{O}$ & $\boldsymbol{C a}(\mathrm{OH})_{2}$ & $\boldsymbol{C}_{3} \boldsymbol{S}_{2} \boldsymbol{H}_{3}$ & $\boldsymbol{C}_{3} \boldsymbol{A H}_{6}$ & $\boldsymbol{C}_{3} F H_{6}$ \\
\hline $\begin{array}{c}\text { Molecular } \\
\text { Weight } \\
(\mathrm{g} / \mathrm{mol})\end{array}$ & 18.0 & 74.1 & 228.2 & 378.1 & 432.8 \\
\hline
\end{tabular}

\subsection{Optimum replacement of cement by fly ash and long-term strength activity index}

\subsubsection{Optimum replacement of cement by fly Ash}

In this technical paper the optimum replacement of cement by fly ash (FA) will be considered by the complete consumption of calcium hydroxide $(\mathrm{CH})$ from hydration of main minerals in cement by the main chemical compositions in FA.

Let $f C_{f}, f S_{f}$ and $f A_{f}$ be the fraction of $C, S$ and $A$ in FA, respectively and $r_{f}$ be the fractional replacement of cement by $\mathrm{FA}$, then the fractional calcium hydroxide $(\mathrm{fCH})$ from hydration of cement in unit weight replaced by FA with the ratio $r_{f}$ would be

$$
\begin{aligned}
& f C H \cdot\left(1-r_{f}\right) . \\
& \quad f C H=f C_{3} S \cdot r_{C H-C_{3} S}+f C_{2} S \cdot r_{C H-C_{2} S} \\
& -f C_{4} A F \cdot r_{C H-C_{4} A F}
\end{aligned}
$$

Where $f C_{3} S, f C_{2} S$ and $f C_{4} A F$ are the fraction of $C_{3} S, C_{2} S$ and $C_{4} A F$ in cement per unit weight, respectively. $\quad r_{\mathrm{CH}-\mathrm{C}_{3} \mathrm{~S}}, r_{\mathrm{CH}-\mathrm{C}_{2} \mathrm{~S}}$ and $r_{\mathrm{CH}-\mathrm{C}_{4} \mathrm{AF}}$ are the ratios of $\mathrm{CH}$ from the hydration reactions of $\mathrm{C}_{3} S$, $C_{2} S$ and $f C_{4} A F$, respectively. Their values are:

$$
\begin{gathered}
r_{C H-C_{3} S}=\frac{3 \cdot w_{C H}}{2 \cdot w_{C_{3} S}}=0.48678 \\
r_{C H-C_{2} S}=\frac{w_{C H}}{2 \cdot w_{C_{2} S}}=0.21509 \\
r_{C H-C_{4} A F}=\frac{2 \cdot w_{C H}}{w_{C_{4} A F}}=0.30677
\end{gathered}
$$

Where $w_{C H}, w_{C_{3} S}, w_{C_{2} S}$ and $w_{C_{4} A F}$ are molecular weight of $\mathrm{CH}, \mathrm{C}_{3} \mathrm{~S}, \mathrm{C}_{2} \mathrm{~S}$ and $\mathrm{C}_{4} \mathrm{AF}$, respectively (See Table 2 and 4).

Since calcium oxide $(\mathrm{CaO})$ can be soluble in water and yield calcium hydroxide as shown in Eq. (9) and (10) and the $\mathrm{SiO}_{2}$ content in FA is usually much more than $\mathrm{CaO}$, it might be assumed that amount of $\mathrm{SiO}_{2}$ in FA is always more than the amount required for the pozzolanic reaction with $\mathrm{CaO}$ in FA itself, there will be adequate residual amount of $\mathrm{SiO}_{2}$ to react with the residual calcium hydroxide from hydration of cement (see Eq. (11) and (12)). aluminum oxide $\left(\mathrm{Al}_{2} \mathrm{O}_{3}\right)$ in FA can also react with the residual calcium hydroxide from hydration of cement (see Eq. (13) and (14)).

The residual $\mathrm{CH}$ from Eq. (15) can be completely consumed in pozzolanic reactions with $\mathrm{SiO}_{2}$ and $\mathrm{Al}_{2} \mathrm{O}_{3}$ as shown in Eq. (19).

$\left(1-r_{f}\right) \cdot f C H=\left(f S_{f}-f C_{f} \cdot r_{C S}\right) \cdot r_{S C H}+f A_{f} \cdot r_{f} \cdot r_{A C H}$

where $r_{S C H}=\frac{3 w_{C H}}{2 w_{S}}=1.84986$ and $\quad r_{A C H}=\frac{3 w_{C H}}{2 w_{A}}$ $=1.09003$ are the ratio of $\mathrm{SiO}_{2}$ and $\mathrm{Al}_{2} \mathrm{O}_{3}$ to react with $\mathrm{Ca}(\mathrm{OH})_{2}$, respectively.

Let

$$
f S_{f}^{\prime}=f S_{f}-f C_{f} \cdot r_{C S}
$$

Where $r_{C S}$ is the ratio by weight of $C$ to $S$ for complete pozzolanic reactions of $\mathrm{SiO}_{2}$ whose value is given in Eq. (21).

$$
r_{C S}=\frac{3 \cdot w_{C}}{2 \cdot w_{S}}=1.40063
$$

Where $w_{C}$ and $w_{S}$ are the molecular weights of $C$ and $S$, respectively (see Table 3 ).

Then Eq. (19) reduces to:

$$
r_{f}=\frac{f C H}{f C H+f S^{\prime} \cdot r_{S C H}+f A_{f} \cdot r_{A C H}}
$$

\subsubsection{Long-term strength Activity index}


Strength of cement paste is mainly contributed by C-S-H from $C_{3} S$ and $C_{2} S$. Additional contributions are from $C_{3} A H_{6}$, the product of $C_{3} A$ and $C_{4} A F$. With fly ash in binder C-S-H and $\mathrm{C}_{3} \mathrm{AH}_{6}$ from pozzolanic reactions have not been clearly understood in the term of rate of reactions as well as the strength development. It was concluded that $\mathrm{C}-\mathrm{S}-\mathrm{H}$ from pozzolanic reactions had the same structure as C-S-H from hydration of cement [7]. However the rate of hydration of $C_{2} S$ as well as the strength development is much slower at the early age of cement paste than developed from $C_{3} S$. Fortunately the long-term strength of C-S-H developed from $C_{2} S$ is insignificantly lower than that from $C_{3} S$, the long-term strength of $\mathrm{C}-\mathrm{S}-\mathrm{H}$ from the pozzolanic reaction could be assumed to be the average strength of C-S-H from $C_{3} S$ and $C_{2} S$ without significant errors. Furthermore the contribution of $\mathrm{C}_{3} \mathrm{AH}_{6}$ from the hydration of cement and pozzolanic reactions take minor contribution to the overall strength of binder. Therefore the strength of $C_{3} A H_{6}$ can be assumed equal for both type of reactions. Based on the reasons mentioned above and the given values of strength for the age of 360 days [8] the long-term strength activity index ( $S A I$ ) can be defined as the strength of binder paste and the strength of cement paste at the age of 360 days as shown below:

$S A I=\frac{(f a+f b) \cdot\left(1-r_{f}\right)-\left(\frac{f A_{f} \cdot r_{f}}{2 \cdot w A l_{2} O_{3}}\right) \cdot(\alpha \beta-\gamma s)+\left(\frac{f C_{f} \cdot r_{f}}{3 w C a O}\right) \cdot \alpha \beta}{f a}$

$$
\begin{gathered}
f a=\frac{1}{2}\left(\frac{f C_{3} S}{w C_{3} S} \cdot \alpha s+\frac{f C_{2} S}{w C_{2} S} \cdot \beta s\right) \\
+\left(\frac{f C_{3} A}{w C_{3} A}\right) \cdot \gamma s+\left(\frac{f C_{4} A F}{w C_{4} A}\right) \cdot \delta s \\
f b=\left(\frac{f C_{3} S}{2 \cdot w C_{3} S}+\frac{f C_{2} S}{6 \cdot w C_{2} S}-\frac{2 \cdot f C_{4} A F}{3 \cdot w C_{4} A}\right) \cdot \alpha \beta
\end{gathered}
$$

Where $\quad \alpha s=72.0, \quad \beta s=71.265, \quad \gamma s=8.082$, $\delta s=5.143$ and $\alpha \beta=71.6325$.

The long-term strength activity index can be extended for predicting strength Activity index for different ages and different surface areas. The coefficients could be obtained by curve fitting of data from tests carried out by many investigators such as [3,9-12]. Details will be out of the scope of this technical paper and will be discussed in the authors' complete research project [13].

\subsection{Propagation of uncertainty}

\subsubsection{Linear functions}

For a linear function of $\mathrm{n}$ random variables in form of:

$$
g(\underline{X})=a_{0}+\sum_{i=1}^{n} a_{i} \cdot X_{i}
$$

The correlation matrix of $\underline{X}$ is symmetric in form of:

$$
[C]=\left[\begin{array}{cccc}
1 & \rho_{12} & \cdot & \rho_{1 n} \\
\rho_{12} & 1 & \cdot & \rho_{2 n} \\
\cdot & \cdot & \cdot & \cdot \\
\rho_{1 n} & \rho_{2 n} & \cdot & 1
\end{array}\right]
$$

Where $\rho_{i j}$ is the correlation coefficient between $X_{i}$ and $X_{j}$. The covariance term $\sigma_{i j}$ can be expressed in terms of the correlation coefficients:

$$
\sigma_{i j}=\rho_{i j} \cdot \sigma_{i} \cdot \sigma_{j}
$$

Where $\sigma_{i}$ and $\sigma_{j}$ are standard deviations of variables $X_{i}$ and $X_{j}$ respectively. Thus $\sigma_{i}{ }^{2}$ and $\sigma_{j}{ }^{2}$ are variance of variables $X_{i}$ and $X_{j}$, respectively.

Then the variance of $g(\underline{X})$ is:

$$
\sigma_{g}^{2}=\sum_{i=1}^{n} a_{i} \cdot \sigma_{i}^{2}+\sum_{i=1}^{n} \sum_{j=1(j \neq i)}^{n} a_{i} \cdot a_{j} \cdot \rho_{i j} \cdot \sigma_{i} \cdot \sigma_{j}
$$

In the case that variables $\underline{X}$ are uncorrelated variables the variance and the standard variation of $g(\underline{X})$ are reduced to:

$$
\begin{gathered}
\sigma_{g}^{2}=\sum_{i=1}^{n} a_{i} \cdot \sigma_{i}^{2} \\
\sigma_{g}=\sqrt{\sum_{i=1}^{n} a_{i} \cdot \sigma_{i}^{2}}
\end{gathered}
$$

\subsubsection{Nonlinear nunctions and Monte-Carlo simulations}

For a nonlinear function of $\mathrm{n}$ uncorrelated random variables, the standard deviation of $g(\underline{X})\left(\sigma_{g}\right)$ to calculate error propagation, the variance formula [14]:

$$
\sigma_{g}=\sqrt{\sum_{i=1}^{n}\left(\frac{\partial g}{\partial x_{i}}\right)^{2} \cdot \sigma_{x_{i}}^{2}}
$$

For other cases Monte-Carlo simulations may be applied. Then the suitable distributions for $g(\underline{X})$ can be obtained by Goodness-Of-Fit Tests e.g. Chi-Square Errors Test and K-S Test [15]. 


\subsubsection{Optimum replacement of fly ash for cement}

For the sake of further discussions: Let the value of a reduced variable $y_{i}$ of a random variable $X_{i}$ with mean $\left(\mu_{X_{i}}\right)$ and standard deviation $\left(\sigma_{X_{i}}\right)$ be:

$$
y_{i}=\frac{x_{i}-\mu_{X_{i}}}{\sigma_{X_{i}}}
$$

The partial derivative of a function $g(\underline{X})$ with respect to a reduced variable $y_{i}$ is $\frac{\partial g(\underline{x})}{\partial y_{i}}$. By applying the chain rule this term may be rewritten as:

$$
\frac{\partial g(\underline{x})}{\partial y_{i}}=\frac{\partial g(\underline{x})}{\partial x_{i}} \cdot \frac{d x_{i}}{d y_{i}}=\frac{\partial g(\underline{x})}{\partial x_{i}} \cdot \sigma_{X_{i}}
$$

From Eq. (22):

$$
\begin{gathered}
\frac{\partial r_{f}}{\partial y f C_{3} S}=\frac{r_{C H-C_{3} S} \cdot\left(f S_{f}^{\prime} \cdot r_{S C H}+f A_{f} \cdot r_{A C H}\right)}{\left[f C H+f S_{f}^{\prime} \cdot r_{S C H}+f A_{f} \cdot r_{A C H}\right]^{2}} \cdot \sigma_{f C_{3} S} \\
\frac{\partial r_{f}}{\partial y f C_{2} S}=\frac{r_{C H-C_{2} S} \cdot\left(f S_{f}^{\prime} \cdot r_{S C H}+f A_{f} \cdot r_{A C H}\right)}{\left[f C H+f S_{f}^{\prime} \cdot r_{S C H}+f A_{f} \cdot r_{A C H}\right]^{2}} \cdot \sigma_{f C_{2} S} \\
\frac{\partial r_{f}}{\partial y f C_{4} A F}=\frac{-r_{C H-C_{3} A F} \cdot\left(f S_{f}^{\prime} \cdot r_{S C H}+f A_{f} \cdot r_{A C H}\right)}{\left[f C H+f S_{f}^{\prime} \cdot r_{S C H}+f A_{f} \cdot r_{A C H}\right]^{2}} \cdot \sigma_{f C_{4} A F} \\
\frac{\partial C H \cdot r_{S C H} \cdot r_{C S}}{\partial y f C_{f}}=\frac{\left.f r_{f}^{\prime} \cdot r_{S C H}+f A_{f} \cdot r_{A C H}\right]^{2}}{f C H+f C_{f C_{f}}} \\
\frac{\partial r_{f}}{\partial y f S_{f}}=\frac{-f r_{S C H}}{\left[f C H+f S_{f}^{\prime} \cdot r_{S C H}+f A_{f} \cdot r_{A C H}\right]^{2}} \cdot \sigma_{f S_{f}} \\
\frac{-f C H \cdot r_{A C H}}{\partial y f A_{f}}=\frac{\left.-f C H+f S_{f}^{\prime} \cdot r_{S C H}+f A_{f} \cdot r_{A C H}\right]^{2}}{[f C} \cdot \sigma_{f C_{f}}
\end{gathered}
$$

Thus:

$$
\sigma_{r_{f}}=\sqrt{\left(\frac{\partial r_{f}}{\partial y f C_{3} S}\right)^{2}+\left(\frac{\partial r_{f}}{\partial y f C_{2} S}\right)^{2}+. .+\left(\frac{\partial r_{f}}{\partial y f A_{f}}\right)^{2}}
$$

\subsection{Reliability analyses}

\subsubsection{Linear limit-state functions}

For a linear function of $\mathrm{n}$ random variables $g(\underline{X)}$ as in form of Eq. (26), the mean $\left(\mu_{g}\right)$ and the standard deviation $\left(\sigma_{g}\right)$ of a vector of normal variables $X$ can be calculated from the equations below:

$$
\begin{gathered}
\mu_{g}=a_{0}+\sum_{i=1}^{n} a_{i} \cdot \mu_{X_{i}} \\
\sigma_{g}=\sqrt{\sum_{i=1}^{n} a_{i}^{2} \cdot \sigma_{X_{i}}{ }^{2}}
\end{gathered}
$$

Then the reliability index $(\beta)$ may be defined as:

$$
\beta=\frac{\mu_{g}}{\sigma_{g}}
$$

Thus the failure probability $\left(p_{f}\right)$ can be calculated from the equation below:

$$
p_{f}=\Phi(-\beta)
$$

Where $\Phi(z)$ is the cumulative probability of the standard normal variable of a $\mathrm{z}$-score. For more details about reliability analyses it is referred to [16].

\subsubsection{Nonlinear limit-state functions and Monte- Carlo simulations}

For general applications where the functions $g(\underline{X})$ are nonlinear and/or random variables are non-normal, then the statistical representation of a limit-state function may be obtained by Monte-Carlo simulations as discussed earlier in section 3.5.2. However the failure probability may be estimated efficiently by Monte-Carlo simulations together with an advanced variance reduction technique such as Importance Sampling Technique as shown below:

$$
p_{f} \cong \frac{1}{N} \sum_{j=1}^{N} I(g(\underline{x})) \cdot \frac{f_{\underline{X}}\left(\underline{x}_{j}\right)}{h_{\underline{Y}}\left(\underline{x}_{j}\right)}
$$

Where $N$ is the number of simulations, $f_{X}(\underline{x})$ is the joint probability density function, $h_{\underline{Y}}(\underline{x})$ is an importance sampling density function, $I(g(\underline{x}))$ is an indicator function whose value equals 1 when $g(\underline{x}) \leq 0$ and equals 0 otherwise.

\section{Mass production of precast concrete}

The statistical data of cement and fly ash available in hands showed significant variation. On one hand the mass production of precast products should be of optimum cost. On the other hand the products should be qualified for all specifications with pre-specified criteria. Therefore the statistical data should be analyzed in advance. For a concrete cast of cement mixed with fly ash, the statistical data available for the materials are summarized in Table 5. 
Table 5. Statistical Properties of main chemical oxide compositions in cement and fly ash.

\begin{tabular}{|c|c|c|c|}
\hline \multirow[b]{2}{*}{$\begin{array}{c}\text { Chemical } \\
\text { Components }\end{array}$} & \multicolumn{2}{|c|}{ fractional } & \multirow[b]{2}{*}{$\begin{array}{c}\text { coefficient of } \\
\text { variation } \\
\text { (stand.dev./mean) }\end{array}$} \\
\hline & mean & $\begin{array}{l}\text { standard } \\
\text { deviation }\end{array}$ & \\
\hline$C_{3} S$ & 0.60877 & 0.01170 & 0.0192 \\
\hline$C_{2} S$ & 0.14857 & 0.01169 & 0.0787 \\
\hline$C_{3} A$ & 0.08473 & 0.00283 & 0.0334 \\
\hline$C_{4} A F$ & 0.10293 & 0.00064 & 0.0062 \\
\hline $\mathrm{CaO}$ (FA) & 0.14124 & 0.08788 & 0.62218 \\
\hline $\mathrm{SiO}_{2}(\mathrm{FA})$ & 0.39910 & 0.10444 & 0.26169 \\
\hline $\mathrm{Al}_{2} \mathrm{O}_{3}(\mathrm{FA})$ & 0.19240 & 0.05763 & 0.29955 \\
\hline
\end{tabular}

Remarks fly ash from Mae Moh, Thailand.

\section{Discussions}

For preliminary analyses all related variables are assumed uncorrelated and normally distributed. The optimum fractional replacement of cement by fly ash is 0.28040 .

The long-term strength Activity index of the optimum replacement of cement by rice hush ash is 1.2480 . The uncertainty of the long-term strength Activity index can be obtained by simple Monte-Carlo simulations. Goodness-Of-Fit tests i.e. Chi-Square Error Test and K-S test indicated that the long-term strength Activity index was best fitted by normal distribution. For optimum replacement of cement by fly ash only the long-term strength Activity index based on 8192 simulations can be represented well by normal distribution with mean value and standard deviation $=1.2480$ and 0.0890 , respectively. The goodness of fit by Chi-Square Error Test is shown in Figure 1.

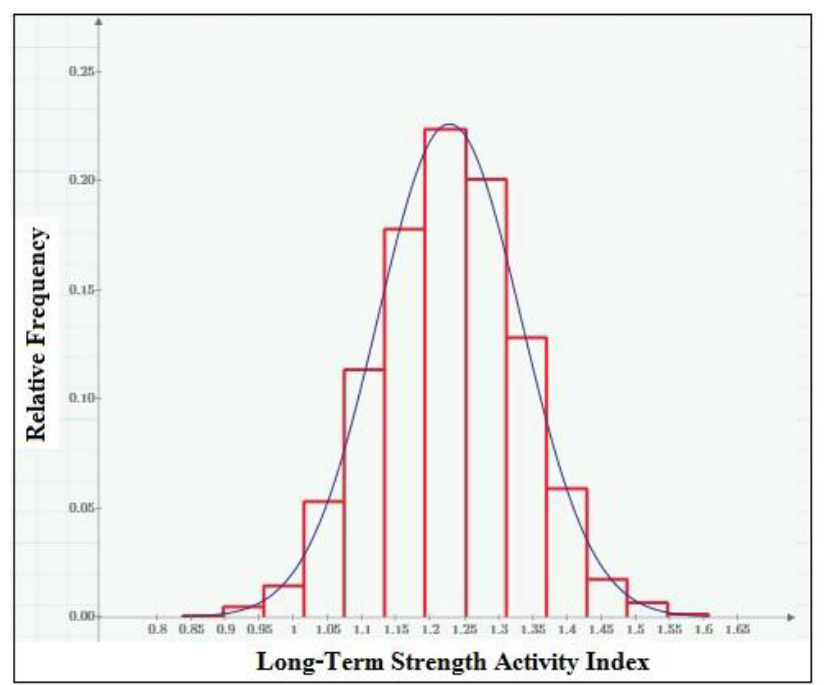

Figure 1. Goodness-Of-Fit Test (Chi-Square Error) for the Optimum Replacement of Cement by Fly Ash.

For the decision based on strength of the concrete the values of failure probability may play an important role. If the failure of the binder paste is defined as the value of the long-term strength Activity index less than 1, then the value of failure probability can be estimated. It can be seen from Eq. (23) that the cross multiplication for $S A I=1$ and forming the limit-state function from the difference of both sides of the equation, then the limitstate function is linear in term of related random variables. Since all these variables are assumed normally distributed, then the reliability index and the corresponding value of failure probability can be obtained easily by using Eq. (44) and Eq. (45), respectively. In other cases the Monte-Carlo simulations together with an Importance Sampling technique may be applied.

For this particular case the reliability index and the value of failure probability for the optimum replacement of cement by fly ash are 2.752 and $\Phi(-2.752)=$ $2.96 \times 10^{-3}$, respectively. Theoretically $S A I$ of the optimum replacement should yield the maximum $S A I$. Since the failure probability in term of $S A I$ is very low for this particular case, a higher or lower value of replacement of cement by fly ash might be possible so that products could be qualified for all specifications.

Once this optimum replacement of cement by fly ash $=0.28040$ is selected, then the propagation of uncertainty in terms of optimum ratio should be also considered. The corresponding standard deviation of this ratio is 0.06214 . Again if the ratio is assumed normally distributed, then the interval of the applied ratio should be $[0.25813,0.30268]$ with the confidence interval $95 \%$ $(0.28040 \pm 1.96 \cdot 0.06214)$. The more precise conclusion may be, again, estimated from Monte-Carlo Simulations and Goodness-Of-Fit tests.

\section{Conclusions}

1) Hydration of main chemical compositions of cement and pozzolanic reactions of minerals in fly ash were reviewed. Data necessary for stoichiometry of hydration- and pozzolanic reactions were also given,

2) Formula for the optimum replacement of cement by fly ash based on the complete consumption of calcium hydroxide from hydration of cement was derived,

3) The long-term strength Activity index for the age of 360 days based on equivalent calcium silicate hydrate was proposed,

4) The propagation of uncertainty of the partial replacement of cement by fly ash in terms of variation of main chemical compositions in cement and fly ash were formulated.

5) Reliability analyses for utilizing the optimum replacement of cement by fly ash were reviewed,

6) The applicability of the proposed concepts was demonstrated based on statistical data of materials available in hand. Results from analyses agreed very well with the tests carried out by other investigators,

7) All the concepts mentioned above could be extended to one other type of pozzolan as well as mixed pozzolan. 


\section{Acknowledgement}

Full financial support and Granting a Professional License of Software Mathcad Prime for Calculation throughout the authors' research projects by Asia Group (1999) Company Limited was cordially acknowledged.

\section{References}

1. K. Kamollertvara, W. Ouypornprasert, Determination of mean values of common distributions in civil engineering from the specifications for mass production, the proceedings of the $7^{\text {th }}$ International Conference on Engineering and Technology ICET-2015, Phuket, June 19-20, 2015, Hat Yai, Songkhla: Prince of Songkla University, Faculty of Engineering (2015) 1-4

2. S. Dumrongsil, B. Chatveera, W. Ouypornprasert, Stiochiometry of pozzolanic reaction, J. Research and Training - Rajmangala Inst. Technolgy. 4(1) (2000) 28-34

3. G. A. Habeeb, H. B. Mahmud, Study on properties of rice husk ash and its use as cement replacement material, Mat. Res. 13(2) (2010)185-190

4. B. W. Langan, K. Weng, M. A. Ward, Effect of silica fume and fly ash on heat of hydration of Portland cement, Cement and Concrete Research 32 (2002) 1045-1051

5. K. Kamollertvara, W. Ouypornprasert, N. Traitruengtatsana, Statistical analyses of optimum partial replacement of cement by rice husk ash based on complete consumption of calcium hydroxide, the Proceedings of RSU International Research Conference 2016, Pathumthani (2016)

6. A. M. Neville, Properties of Concrete, $4^{\text {th }}$ and Final Ed., Addison Wesley Longman Limited, Wessex, London (1995)

7. H. F. W. Taylor, Cement Chemistry, $2^{\text {nd }}$ Ed., Thomas Telford Publishing, Thomas Telford Services, Ltd., London (1997)

8. R. H. Bouge, Chemistry of Portland Cement. New York: Reinhold (1955)

9. H. T. Le, H. M. Ludwig, Effect of rice husk ash and other mineral admixtures on properties of selfcompacting high performance concrete, Materials and design, 89 (2016)156-166

10. N. M. Khalil, E.M. Hassan, E. M. Shakdofa, M. Farahat, Beneficiation of the huge waste quantities of barley and rice husks as well as coal fly ashes as additives for Portland cement, J. Industrial and Engineering Chemistry, 20 (2014)2998-3008

11. A. Nawaz, P. Julnipitawong, P. Krammart, S. Tangtermsirikul, Effect and limitation of free lime content in cement-fly ash mixtures, Constructiona and Building Materials, 102 (2016)515-530

12. B. Chatveera, P. Nimityongskul, Portland cement containing rice husk ash, fly ash and superplasticzer, Suranaree J. Sci. Technol., 1 (1994)109-122

13. W. Ouypornprasert, N. Traitruengtatsana, K. Kamollertvara, The use of rice husk ash and fly ash for partial replacement of cement for mass production of precast concrete products, Internal Working Report No.20 - Asia Research, Development and Innovation Center, Asia Expansion Concrete Product (1993) Co. Ltd., Bangkok (2016)

14. H. H. Ku, Notes on the use of propagation of error formulas. The National Bureau of Standards, 70C(4) (1966) 262

15. W. Ouypornprasert, The proceedings of the International Conference on Computational Mathematics and Modeling (CMM-2002), 22-24 May 2002. Goodness-of-Fit Tests for Common Continuous Distributions in Civil Engineering, Century Park Hotel, Bangkok: Mahidol University and Curtin University of Technology (2002)117-126

16. W. Ouypornprasert, Methods to calculate structural reliability, Internal Working Report No.18, Institute of Engineering Mechanics, University of Innsbruck, Austria (1988) 